DOI: $10.2478 / \mathrm{v} \cdot 10169-012-0008-\mathrm{x}$

\title{
FINITE ELEMENT MODEL UPDATING OF REINFORCED CONCRETE BEAMS WITH HONEYCOMB DAMAGE
}

\begin{abstract}
Z. ISMAIL ${ }^{1}$
A method of detecting honeycombing damage in a reinforced concrete beam using the finite element model updating technique was proposed. A control beam and two finite element models representing different severity of damage were constructed using available software and the defect parameters were updated. Analyses were performed on the finite element models to approximate the modal parameters. A datum and a control finite element model to match the datum test beams with honeycombs were prepared. Results from the finite element model were corrected by updating the Young's modulus and the damage parameters. There was a loss of stiffness of $3 \%$ for one case, and a loss of $7 \%$ for another. The more severe the damage, the higher the loss of stiffness. There was no significant loss of stiffness by doubling the volume of the honeycombs.
\end{abstract}

Key words: damage parameter, FE model, honeycombing, updating, Young's modulus.

\section{INTRODUCTION}

Many structures are built with concrete. It is important to be able to monitor the structural integrity of these structures. Dynamic testing, visual as well as sensors had been employed for this purpose by several researchers like Bagchi [1], CaEtano et al. [2], Doebling et al. [3], Fayyadh et al. [4], Ismail [5], Ismail et al. [6], Ismail et al. [7], Ismail et al. [8], Ismail and ONG [9], Rahman et al. [10], Rahman et al. [11], ReYNOLDS [12]. Mathematical models of structures obtained by many different means had been developed towards this direction. For structures, which are not too complex, models using partial differential equations may be developed. For complex structures, methods such as the transfer matrix and finite element are frequently used. The objective is to produce a model capable of giving an insight into the behavior of the structure. The challenge is to find a simple enough model capable of describing the physical structure while enabling cost effective computational process to achieve as close as possible the real situation. Several methods had been successfully used to detect general damage in concrete structures, one of which was the use of thermal imaging as demonstrated by BHALla et al. [13]. Other methods of detecting general damage had also been suggested

${ }^{1}$ Civil Engineering Department, University of Malaya Lembah Pantai, 50603 Kuala Lumpur, Malaysia, e-mail: zubaidahjka@gmail.com 
by using higher order derivatives of mode shapes. One of the more common defects in concrete is honeycombing. It is the result of improper construction procedures and chemical attacks. Studies on honeycombing damage are generally limited. Some studies on the effect of honeycombing in concrete had been carried out by KHAzEL [14] and OMAR and Clarke [15] which included work on the load carrying capacity and modal response of the affected beams. Several approaches towards system identification of beams with such damage had also been suggested by previous researchers such as Bayraktar et al. [16], Caicedo [17], Devi et al. [18] and Fang et al. [19].

The method using higher order derivatives of mode shapes mentioned above had been studied and successfully applied for honeycombing damage by GaUTHIER [20], Ismail et al. [6], Whalen [21] and Whalen et al. [22]. Higher-order derivative discontinuity method for damage identification had also been experimentally validated. This discontinuity method had been applied to a bridge damage detection problem. Other methods which had been used for structural damage detection are the linear matrix inequality methods as applied by ABDALLa [23] and the released strain method by CASTRO et al. [24]. Dynamic analysis of generally supported beams using Fourier series was conducted by Wang and LiN [25], and free vibrations of beams with general boundary conditions was conducted by Li [26]. The application of Chebyshev's series to solution of non-prismatic beam vibration problem had also been employed by RUTA [27, 28] to detect damage. FEM model updating had been widely used to study damage in concrete structures. The fundamentals of the FEM method are well documented by Grandin Jr, [29] in the literature and in the Manual by TNO [30]. WALTER [31] demonstrated that data could be generated and validated before an actual model is prepared.

Regressed mode shapes using Fourier series and Fourier series plus a polynomial; the Chebyshev's series and the Chebyshev's series rational had also been successful in detecting damage in beams. The local stiffness indicator (LSI) defined as the absolute value of $\lambda^{4}$ had also been successfully applied to locate damage in RC beams. The FEM method for model updating had been verified by Friswell and MotTERSHEAd [32]. The numerical procedures and application aspects of updating analytical models had been reviewed by CHEN and EwINs [33]; and the FEM model updating using various modal parameters had also been carried out by several researchers like LiNK [34]. Examples were updating of FEM model by means of normal mode parameters could be seen through work by NieDBAL et al. [35]. FEM adjustment using experimental modal data and updating using FRF data had been conducted by BERGER et al. [36] and LiN and Ewins [37]. Other methods of damage assessment that had been used are damage functions by Teughels et al. [38], eigenstructure assignment and eigenvalue embedding techniques for vibrating systems by Biswa [39], eigenvalue and strain energy residuals using multi-objective optimization technique by JAISHI and ReN [40], and sensitivity-based using constrained optimization with a trust region algorithm by BAKIR et al. [41]. The limitations of the methods had also been pointed out by GoLA et al. [42] and Ganey et al. [43]. The method had been successfully applied in damage localization and updating using multi-response NDT data as demonstrated by SANAYEI 
et al. [44]. Experience with different procedures for updating structural parameters using test data had also been reported by Link and ZHANG [45]. Updating of existing steel bridge based on structural health monitoring had also been conducted by $\mathrm{He}$ et al. [46].

In the current study, finite element models specifically for honeycombs were constructed and simply updated by means of varying the Young's modulus and damage parameters to match the experimental results. Linear static, nonlinear, and eigenvalue analyses were also performed on the finite element models so that modal parameters could be approximated.

\section{Material AND METHODS}

\subsection{Finite Element Models}

General-purpose finite element software, based on the displacement method, was utilized to model the reinforced concrete beams in two dimensions. This software was able to investigate the physical and mechanical behavior of the beams. A feature of this software was that reinforcing bars were modeled as special bar elements [30].

Two-dimensional finite elements models, 2.2 meters long, $250 \mathrm{~mm}$ deep, and divided into fifty-five divisions along the length, were constructed to represent control, datum, and defect beams with honeycombs. A typical model that was constructed using the software had the line elements (L1 - L10), the surface element (S1), and meshing division (55 along the $\mathrm{x}$ axis, 4 along the $\mathrm{y}$ axis, 1 for the constraints, and 1 for the reinforcement). This is shown in Fig. 1a-Fig. 1d. It is further described below and used to verify the algorithm proposed in determining the location of the defect.

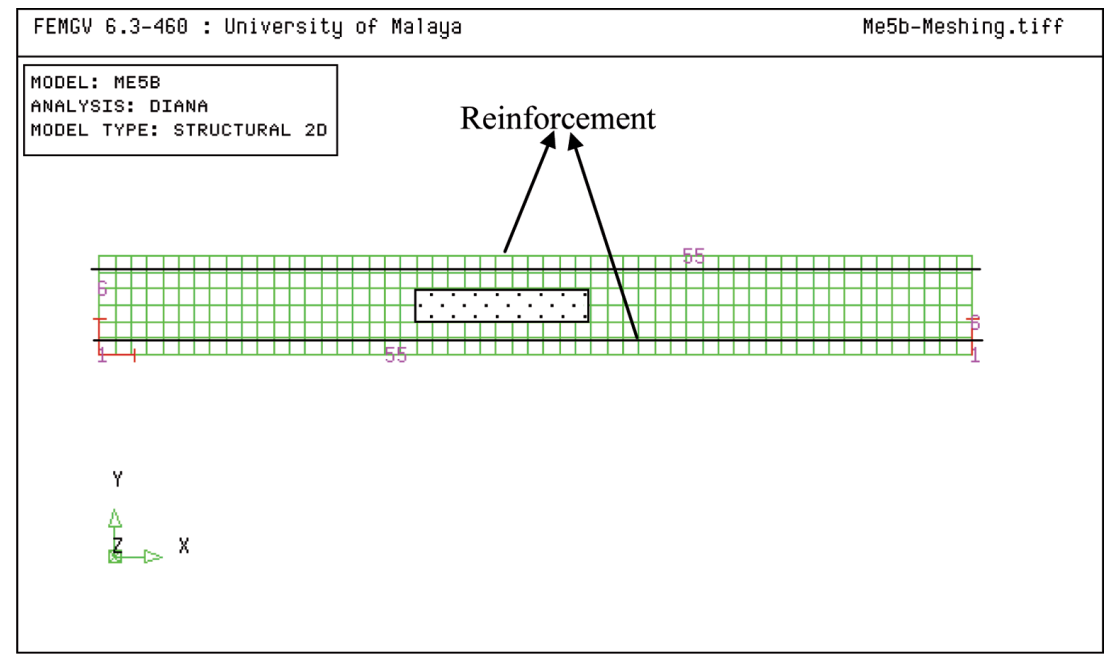

Fig. 1a. Location of reduced Young's modulus at mid-span position: a) FE-L5 


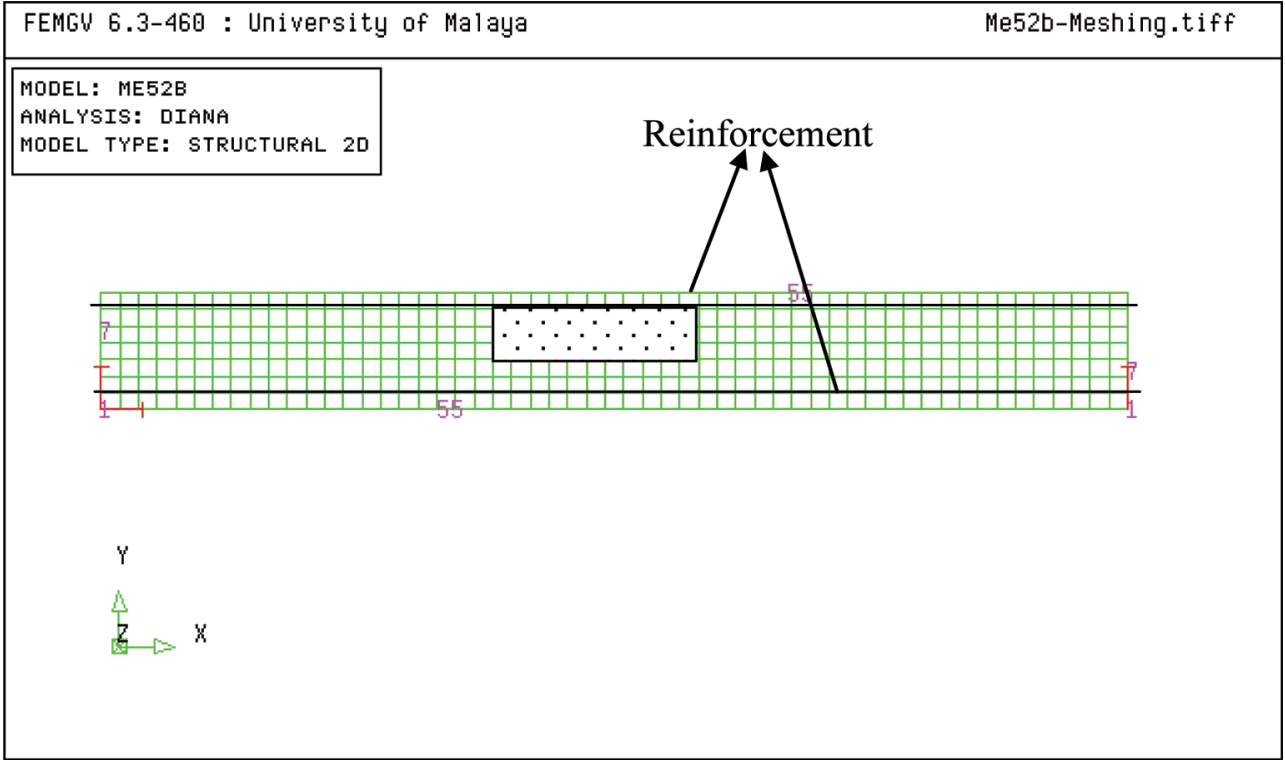

Fig. 1b. Location of reduced Young's modulus at mid-span position: b) FE-L5x2

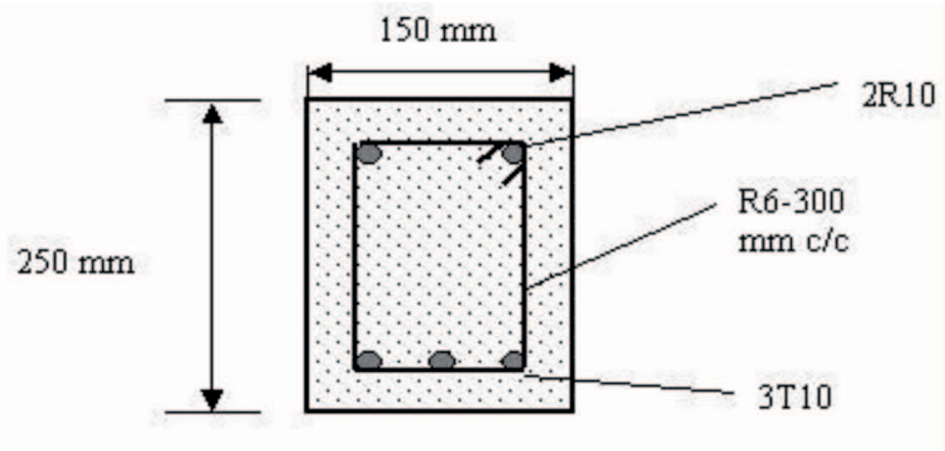

Fig. 1c. Cross-section of test beam

Experimental verification was conducted by preparing test beams with the same dimensions and also with honeycombs of the same dimensions. Load tests and modal testing were conducted on these beams. The dimensions of the honeycomb are given in Table 1, and the modal testing set-up is given in Fig. 2.

\subsection{Model CHARACTERISTics}

Quadrilateral plane stress elements with four nodes and linear in behavior were chosen for the concrete. The reinforcement was considered as a line element type with two 
(i)

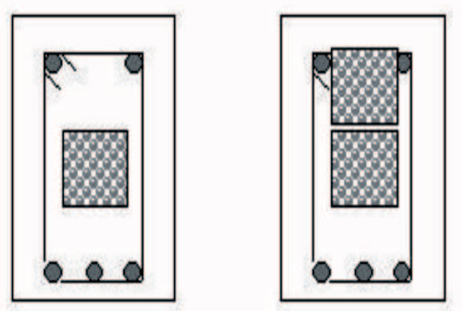

(ii)

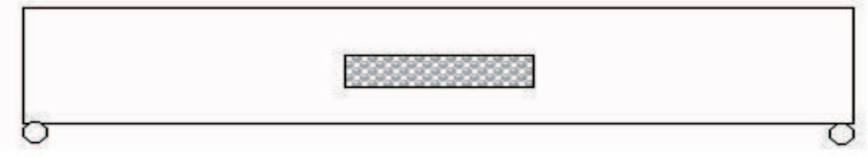

(iii)

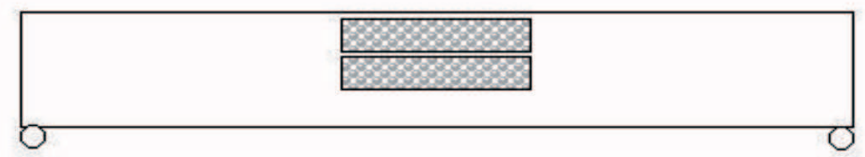

Fig. 1d. (i) Cross section: Defect beam L5 and Defect beam L5x2

(ii) Side section: Defect beam L5 and Defect beam L5x2
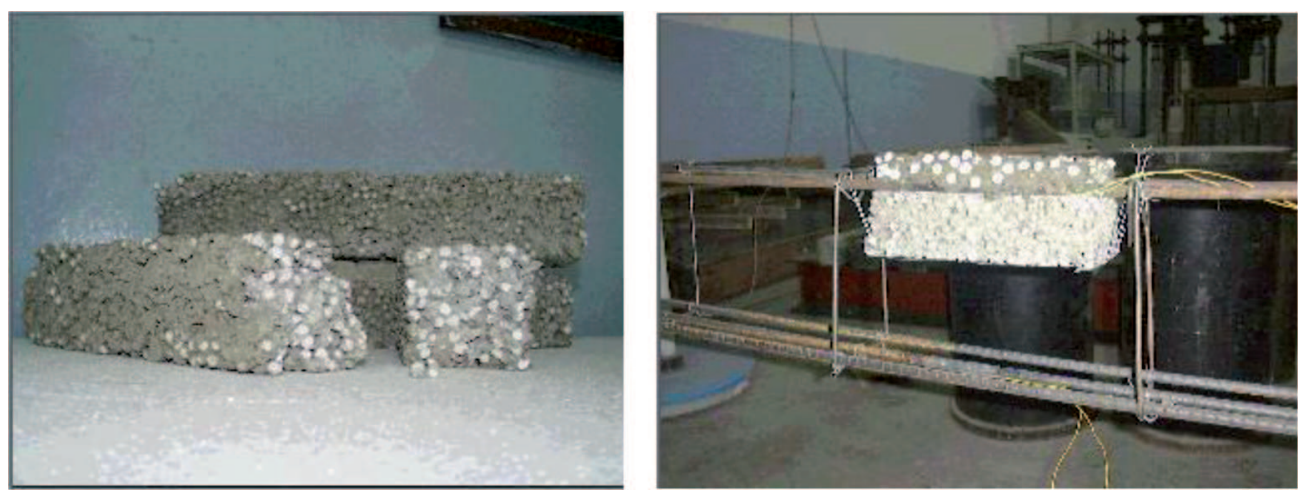

Fig. 2a. Mortar blocks representing honeycombs 

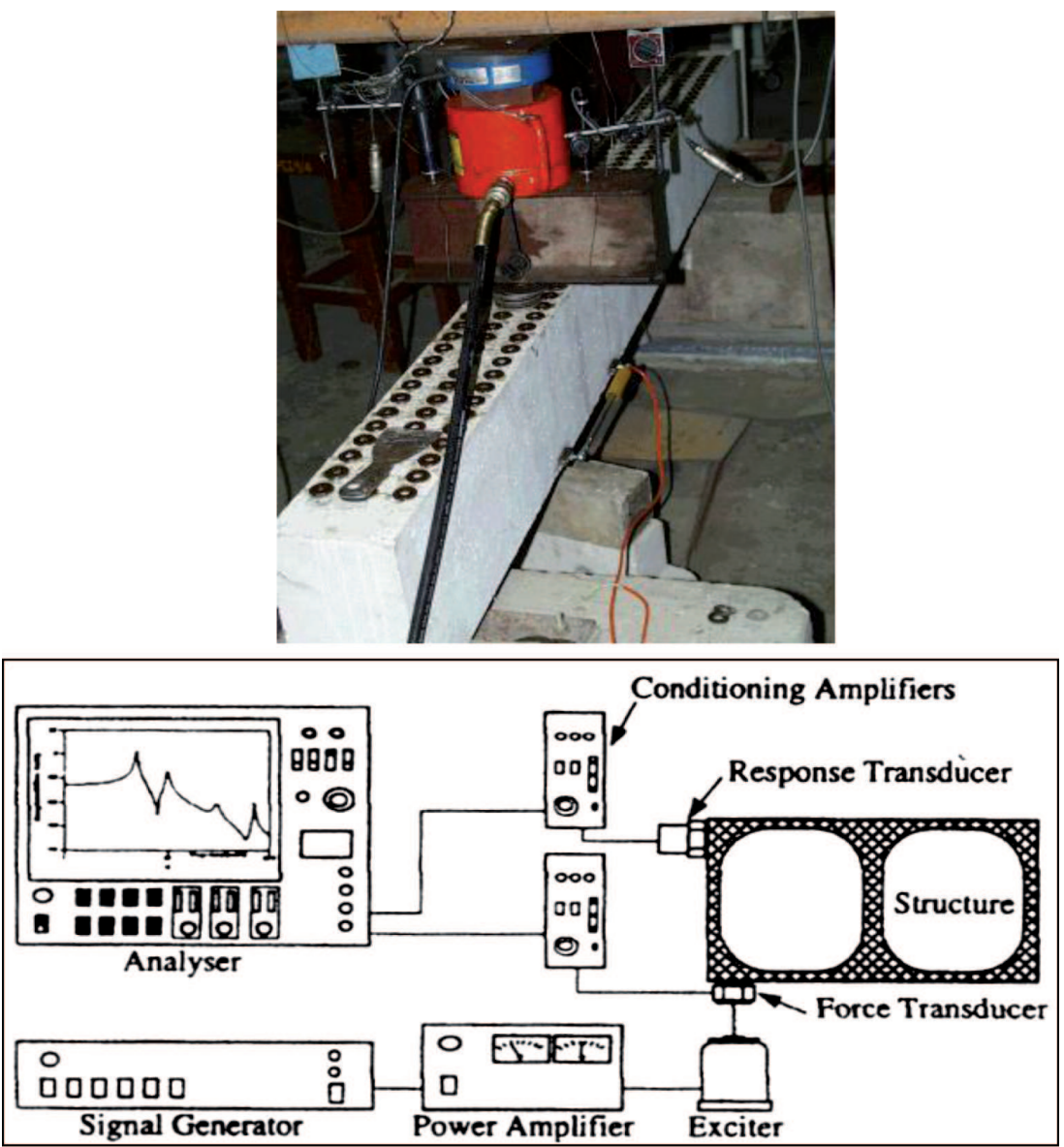

Fig. 2b. Modal Testing set-up

nodes and was referred to as a special bar element. The physical and material properties of the concrete were isotropic linear elastic with a Poisson's ratio of 0.2, mass density of $2400 \mathrm{~kg} / \mathrm{m}^{3}$, and Young's modulus on a case-to-case basis. The models had a constant thickness of $0.15 \mathrm{~m}$. The reinforcement bars were embedded in the quadrilateral elements and had a cross-sectional area of $15.708 \times 10^{-5} \mathrm{~m}^{2}$ ( 2 bars), Young's modulus of $200 \times 10^{9} \mathrm{~N} / \mathrm{m}^{2}$, and von Mises yield value of $440 \times 10^{6} \mathrm{~N} / \mathrm{m}^{2}$. Experimentally the beams were supported by rollers. For model updating purposes these conditions were modeled as a single point elastic spring with stiffness $10^{8} \mathrm{~N} / \mathrm{m}^{2}$ in the $x$ and $y$ direction at the left support, and in the $y$ direction at the right support. The self-weight was computed by taking gravitational acceleration as $9.81 \mathrm{~m} / \mathrm{s}^{2}$ in the $-y$ direction. The summary of the general characteristics of the finite element models is shown in Table 1. 
A section of the typical finite element model showing its general characteristics had the structural element types Q8MEM (quadrilateral plane stress, 4 nodes, linear), REIBAR (embedded reinforcement), and SP2TR (orthotropic geometry, translation spring, 2 nodes), the material and physical properties MA1 and PH1 (for concrete) and $\mathrm{PH} 2$ and MA2 (for reinforcement), respectively, and the constraints CO1 (for supports). The element numbering and the loads (self-weight) were also shown. Bond slip was not modeled since there was no such failure.

A main model with no defect and its variation with a segment of the quadrilateral elements having a reduced Young's modulus was considered. The model was constructed using three layers of surface with thickness $30 \mathrm{~mm}, 90 \mathrm{~mm}$, and $30 \mathrm{~mm}$ consecutively to accommodate the thickness of the segment with a reduced Young's modulus of $90 \mathrm{~mm}$. This segment was located at the mid-span section to represent the honeycombing region, with varying overall height about the neutral axis of the model. Two mortar blocks FE-L5 and FE-L5 $\times 2$ with different volumes to reflect different severity of honeycomb damage were constructed. The dimensions of the honeycombs are given in Table 1.

Table 1

Characteristics of the finite element models.

\begin{tabular}{|c|c|c|c|}
\hline \multirow{4}{*}{ Element Types } & \multicolumn{2}{|c|}{ Concrete } & Reinforcement \\
\hline & \multicolumn{2}{|c|}{ Quadrilateral plane stress } & Line element \\
\hline & \multicolumn{2}{|l|}{ 4-nodes } & 2-nodes \\
\hline & \multicolumn{2}{|l|}{ Linear } & Reinforcement bars \\
\hline \multirow[t]{2}{*}{ Physical properties } & \multicolumn{2}{|l|}{ Isotropic } & Reinforcement bars \\
\hline & \multicolumn{2}{|c|}{ Uniform thickness $=0.15 \mathrm{~m}$} & Cross-sect area $=15.708 \times 10^{-5} \mathrm{~m}^{2}(2$ bars $)$ \\
\hline \multirow[t]{4}{*}{ Material properties } & \multicolumn{2}{|c|}{ Isotropic linear elasticity } & Embedded reinforcement \\
\hline & \multicolumn{2}{|c|}{ Poisson's ratio $=0.2$} & Young's modulus $=200 \times 10^{9} \mathrm{~N} / \mathrm{m}^{2}$ \\
\hline & \multicolumn{2}{|c|}{ Mass density $=2400 \mathrm{~kg} / \mathrm{m}^{3}$} & Yield $=$ von Mises \\
\hline & \multicolumn{2}{|c|}{$\mathrm{E}=$ case to case basis } & Yield value $=440 \times 10^{6} \mathrm{~N} / \mathrm{m}^{2}$ \\
\hline Support conditions & \multicolumn{3}{|c|}{$\begin{array}{l}\text { Single point elastic springs in the } x \text { and } y \text { direction at the } \\
\text { left and right supports, resting on fixed constraints in the } x \text { and } y \text { direction } \\
\text { at the right support and in the } y \text { direction at the left support. }\end{array}$} \\
\hline \multicolumn{2}{|l|}{ Spring stiffness } & \multicolumn{2}{|l|}{$=10^{8} \mathrm{~N} / \mathrm{m}^{2}$} \\
\hline \multicolumn{2}{|l|}{ Acce. due to gravity } & \multicolumn{2}{|c|}{$=9.81 \mathrm{~m} / \mathrm{s}^{2}$ in the $-\mathrm{y}$ direction } \\
\hline \multicolumn{2}{|c|}{ Honeycomb dimensions } & FE-Control & FE-L5 FE-L5×2 \\
\hline & Length (L) mm & 0 & 440 \\
\hline & Width (W) mm & 0 & 90 \\
\hline & Depth $(\mathrm{H}) \mathrm{mm}$ & 0 & 180 \\
\hline \multicolumn{2}{|c|}{ Beams' updated Young modulus } & N/A & $26 \times 10^{9} \quad 25 \times 10^{9}$ \\
\hline \multicolumn{2}{|c|}{ Honeycombed updated Young modulus } & N/A & $27 \times 10^{9} \quad 7 \times 10^{6}$ \\
\hline
\end{tabular}




\subsection{Finite Element Analyses}

Linear static analysis was first performed on the finite element models. This involved the evaluation and assembly of the finite element model, and setting up the element stiffness matrices and the load vectors. A direct Gauss decomposition method using the sparse Cholesky routine was used to produce displacements, reactions, strains and stresses for the various cases.

Only eigenvalue analysis was performed on the control finite element model and finite element model with a section of reduced Young's modulus. The natural frequencies and corresponding mode shapes needed for further processing were calculated. The solution method to solve the generalized or the standard eigenproblem used was the subspace iteration method. This method required a symmetric and positive definite system matrix. Consistent element mass matrices were utilized for the free vibration frequency analysis.

\subsection{Updating Procedures}

A datum and a control finite element model to match the datum test beams with honeycombing were prepared. Since results from the FE model frequently show discrepancies in both natural frequencies and mode shapes due to discretization and configuration errors respectively, updating or correcting of the data was required. In this study the discrepancies were found to be about ten percent on first natural frequency. Necessary adjustments on the Young's modulus and support conditions for the datum beam were done in order to obtain similar values of natural frequencies and similar profile of the mode shapes between the finite element models and the test beams. Two types of updating were done: the first one was by updating the Young's modulus, $E$. The second was by updating the Young's modulus for the segment of the quadrilateral elements representing honeycombed concrete.

\subsubsection{Updating the Young's modulus}

To update the Young's modulus, the first step was to adjust the support conditions in order to get the modal assurance criterion, $\left[M A C_{\tilde{x} x}\right]_{i i}=\frac{\left(\left\{\tilde{\varphi}_{i}^{x}\right\}^{T}\left\{\varphi_{i}^{x}\right\}\right)^{2}}{\left(\left\{\tilde{\varphi}_{i}^{x}\right\}^{T}\left\{\tilde{\varphi}_{i}^{x}\right\}\right)\left(\left\{\varphi_{i}^{x}\right\}^{T}\left\{\varphi_{i}^{x}\right\}\right)}$, values to within $75 \%$ of the mode shapes of the test beam. Next, the natural frequencies and mode shapes for different Young's modulus were generated. Two criteria were used to determine which value of Young's modulus was to be chosen for the datum finite element beam. They were, that the first natural frequency of the finite element model was within $10 \%$ difference of the first natural frequency of the datum test beam; and $\left|\frac{\partial E}{E}\right|=\frac{2}{m} \sum_{i=1}^{m}\left(\frac{\partial \omega_{i}}{\bar{\omega}_{i}}\right)$

( $m=$ the first $m$ modes) was also within $10 \%$. 
The Young's modulus for the models with honeycombs adjusted to $27 \times 10^{9} \mathrm{~N} / \mathrm{m}^{2}$ as shown also in Table 1. The Young's modulus from the finite element models chosen to match the damaged test beams followed the same criteria. The Young's modulus for beam L5 and L5 $\times 2$ were chosen as $26 \times 10^{9} \mathrm{~N} / \mathrm{m}^{2}$ and $25 \times 10^{9} \mathrm{~N} / \mathrm{m}^{2}$, respectively as shown in Table 1 . These guidelines follow the procedure proposed by previous researchers [25].

\subsubsection{Updating damage parameters}

Trials runs were made with reduced Young's modulus ranging from $27 \times 10^{8} \mathrm{~N} / \mathrm{m}^{2}$ to $27 \times 10^{5} \mathrm{~N} / \mathrm{m}^{2}$. Two criteria were also used to determine which value of Young's modulus was to be chosen for the segment of the quadrilateral elements representing honeycombed concrete. The percentage difference of natural frequencies for all modes was within $10 \%$, and $|\partial E / E|$ was the smallest, which was within $2.5 \%$.

The updated value of the Young's modulus for the honeycombed concrete was $7.0 \times 10^{6} \mathrm{~N} / \mathrm{m}^{2}$ as shown in Table 1 .

\section{REsUlts AND DISCUSSION}

The following are results of EI and detection of damage locations for the finite element models of the beams with honeycombs represented by FE-L5 and FE-L5×2. EI's for the models were derived by using the $E$ values obtained from two different methods of updating. For detecting the damage locations, the values of $\lambda$ were plotted in Fig. $5 \mathrm{~d}$ as bar charts.

\subsection{Updating Young's Modulus}

Several values of Young's modulus were tried for the undamaged finite element model in order to obtain a set of results as close as possible to the set of results for the datum and honeycombed test beams by comparing their natural frequencies and mode shapes. Frequency shifts and Modal Assurance Criterion (MAC) were utilized as the methods of comparison. The following are results for all test beams based on their frequency shifts and MAC values. Fig. $3 b$ shows the MAC values for the datum beams and control beams. For other cases, the comparison made was between finite element model with no defects and test beams with defects.

The values for mode 5 and mode 6 were omitted in the calculation of the percentage difference compared to the mean $\frac{\delta \omega}{\bar{\omega}}$ because mode 5 and mode 6 were not available from the experiment with the control beam and beam L5x2.

Table 2 shows the percentage difference in the natural frequencies of an updated finite element model using $E=27 \times 10^{9} \mathrm{~N} / \mathrm{m}^{2}$ compared to the control beam, with the corresponding MAC for mode 1 to 10 . The percentage $\frac{\delta \omega}{\omega}$ ranged from $-14.95 \%$ for 
mode 2 to $4.25 \%$ for mode 10 . Compared to the mean frequency $\frac{\delta \omega}{\bar{\omega}}$ the percentage ranges from $3.41 \%$ for mode 2 to $8.67 \%$ for mode 10 with the $\left|\frac{\partial E}{E}\right|$ of $5.28 \%$. There were no values obtained for mode 5. The MAC ranged from 0.9772 for mode 1 to 0.7297 for mode 9 .

The percentage differences in the natural frequencies of two updated finite element models; one using $E=26 \times 10^{9} \mathrm{~N} / \mathrm{m}^{2}$ (Case 1) and the other using $E=25 \times 10^{9} \mathrm{~N} / \mathrm{m}^{2}$ (Case 2) compared to the values for beam L5 and L5 $\times 2$, respectively were obtained. The percentage difference $\frac{\delta \omega}{\omega}$ ranged from $-8.04 \%$ for mode 1 to $15.33 \%$ for mode 2 for the first case and $-14.89 \%$ for mode 2 to $4.62 \%$ for mode 10 for the second case. The percentage difference compared to the mean frequency $\frac{\delta \omega}{\bar{\omega}}$ ranged from $3.52 \%$ for mode 2 to $7.71 \%$ for mode 10 with the $\left|\frac{\partial E}{E}\right|$ of $4.48 \%$ for the first case and $-3.41 \%$ for mode 2 to $9.39 \%$ for mode 10 with the $\left|\frac{\partial E}{E}\right|$ of $6.52 \%$ for the second case.

Comparison between the finite element beam and the test beam showed that the first natural frequency of the finite element model chosen was within $10 \%$ difference of the first natural frequency of the datum test beam and $\left|\frac{\partial E}{E}\right|$ chosen was also within $10 \%$.

\subsection{EI from Updating Young's Modulus}

This section presents the results of EI after updating the Young's modulus. After finding the matching results for all test beams based on their frequency shifts and MAC values, the global $E I$ values were obtained by multiplying the respective $E$ values with the moment of inertia, $I$.

Table 3 shows the EI values for the control model with $E=27 \times 10^{9} \mathrm{~N} / \mathrm{m}^{2}$ and model FE-L5 and FE-L5 $\times 2$ obtained with values used in the updating process. The EI for the control model was $5.8409 \times 10^{6} \mathrm{Nm}^{2}$. The relative stiffness for FE-L5 as compared to the control was 0.96 or a loss of $4 \%$, and the relative stiffness for FE-L5 $\times 2$ as compared to the control beam was 0.93 or a loss of $7 \%$. It was seen that beam FE-L5 $\times 2$, which represented a higher proportion of damage exhibits a higher drop of global flexural stiffness.

The flexural stiffness was obtained for each case using the $E$ values from the up-dating process. It was seen that there was a loss of stiffness of $3 \%$ for the case of FE-L5, and a loss of $7 \%$ for the case of FE-L5 $\times 2$. The more severe the damage, as evidenced by the higher volume of honeycombs, the higher the loss of stiffness. 


\subsection{Updating Damage Parameters}

Fig. 3 and Fig. 4 show the natural frequencies for the control model, FE-L5 and FE-L5 $\times 2$ with an updated Young's modulus for the honeycombed concrete of $7.0 \times 10^{6}$ $\mathrm{N} / \mathrm{m}^{2}$ for mode 1 to 10 . The percentage difference in natural frequency for FE-L5 ranged from $0.01 \%$ for mode 3 to $7.85 \%$ for mode 7 with $\frac{2}{10} \Sigma \frac{\delta \omega}{\omega}$ value of $9.58 \%$. For beam FE-L $5 \times 2$ the percentage difference in natural frequency ranged from $-1.75 \%$ for mode 3 to $7.76 \%$ for mode 7 with $\frac{2}{10} \Sigma \frac{\delta \omega}{\omega}$ value of $7.97 \%$.
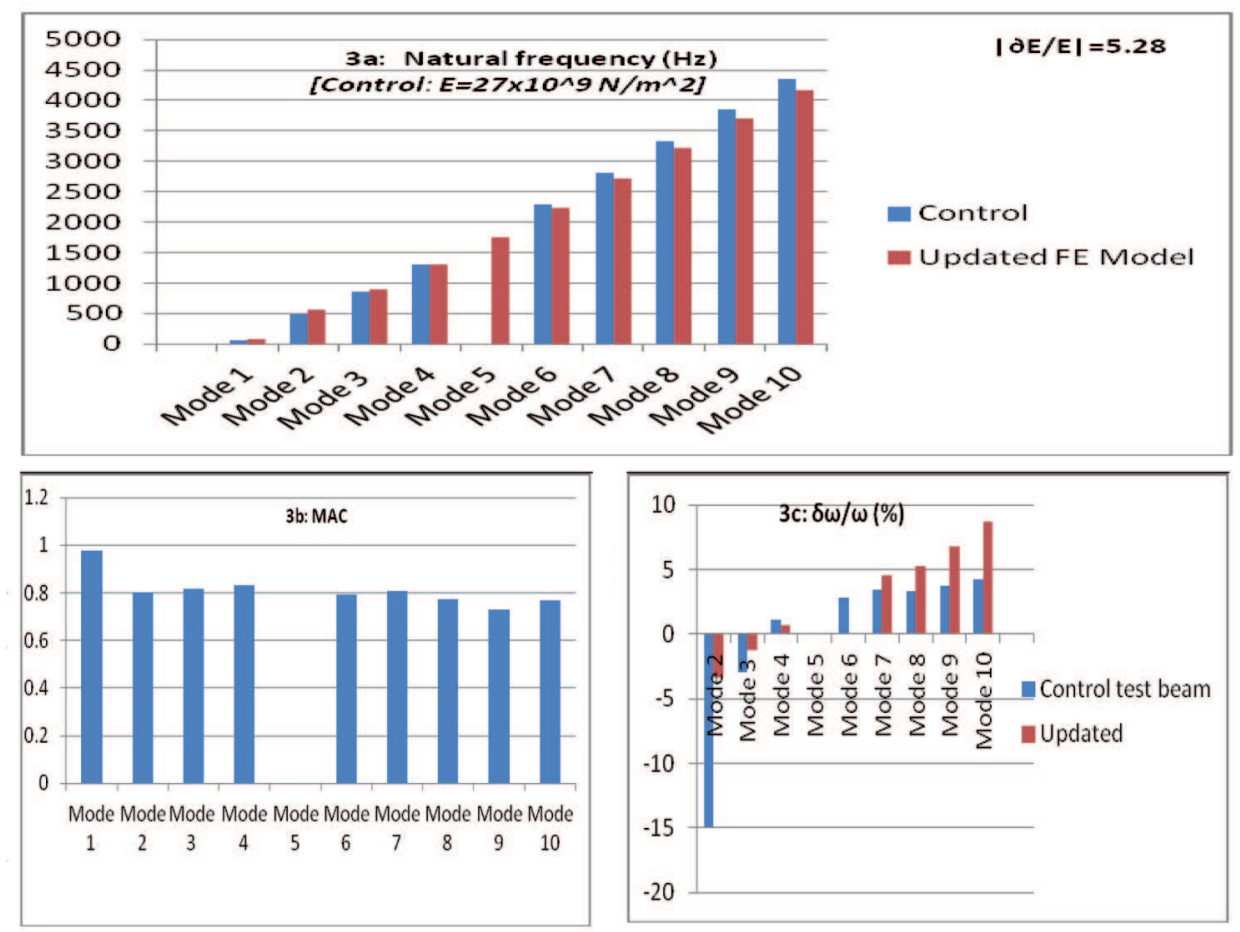

Fig. 3. Data for control and updated model

The percentage differences in the natural frequencies of two updated finite element models using $E=27 \times 10^{9} \mathrm{~N} / \mathrm{m}^{2}$ and $E=7.0 \times 10^{6} \mathrm{~N} / \mathrm{m}^{2}$ for the honeycombed concrete; one was FE-L5 (Case 1) and the other was FE-L5×2 (Case 2) compared to test beam L5 and L5 $\times 2$, respectively were obtained. The percentage difference in the natural frequency ranged from $-13.63 \%$ for mode 2 to $10.22 \%$ for mode 7 for the first case and $-14.94 \%$ for mode 2 to $9.48 \%$ for mode 7 for the second case. The MAC values for the first case ranged from 0.9387 for mode 1 to 0.5213 for mode 9 and for the second case the values ranged from 0.9491 for mode 1 to 0.7160 for mode 7 . 

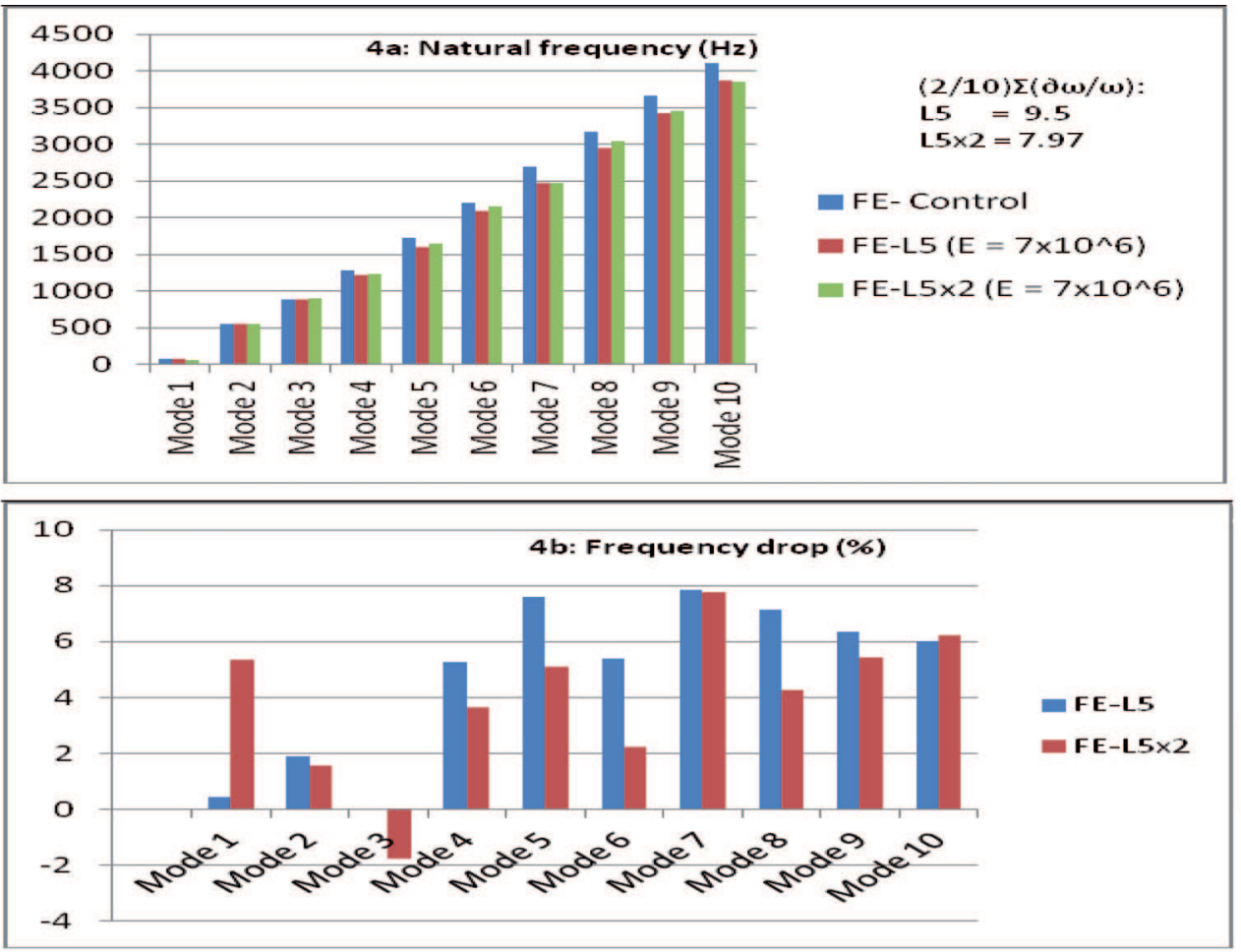

Fig. 4. Natural frequency $(\mathrm{Hz})$

For both honeycombed beams, the values of $\frac{2}{10} \Sigma \frac{\delta \omega}{\omega}$ were within $10 \%$, and that for mode 1 the percentage drop of natural frequency for beam FE-L5 $\times 2$ which represented a higher proportion of damage was higher compared to the value for beam FE-L5.

\subsection{EI from Updating Damage Parameters}

The global EI values from updating parameters were derived by regressing the eigenvectors with the general solution to obtain the parameter $\lambda$, and rearranging the equation $\lambda^{4}=\frac{\rho A \omega^{2}}{E I}$.

Fig. 5d shows the $\lambda$ values obtained from non-linear regression for the control model and model FE-L5 and model FE-L5 $\times 2$ for mode 2 . Mode 2 was used instead of mode 1 since the $\mathrm{R}^{2}$ values for mode 2 were better than those for mode 1 . The value for the control was 4.0060, for FE-L5 the value was 3.9957 and for FE-L5 $\times 2$ the value was 4.0484 with the corresponding values of $R^{2}$ of $0.9999,0.9999$ and 0.9994 respectively. 


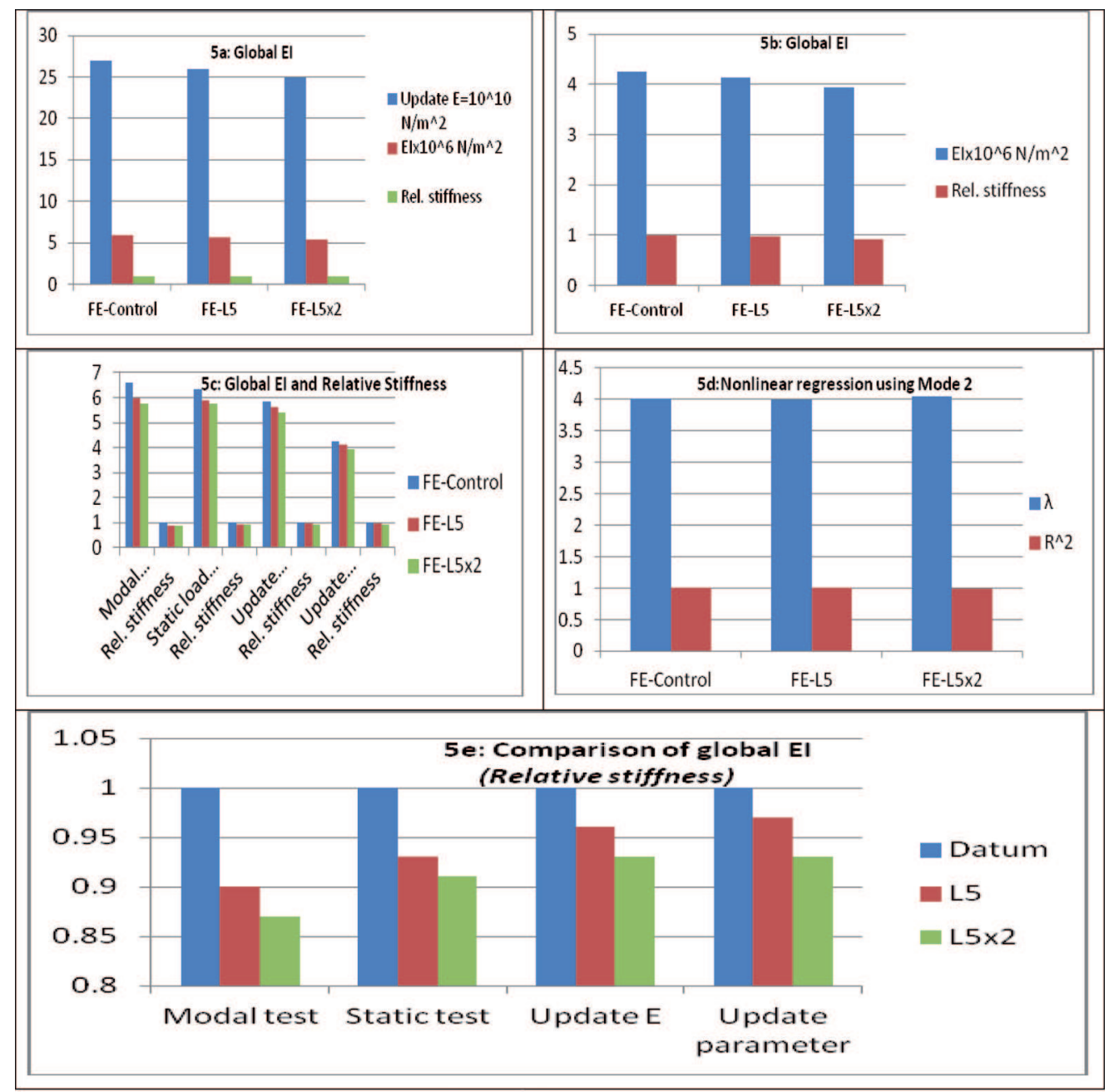

Fig. 5. Global EI values

The global EI for the control model and model FE-L5 and model FE-L5 $\times 2$ were obtained from the Young's modulus used in the updating process. The global EI for the control model was $4.2456 \times 10^{6} \mathrm{Nm}^{2}$ as shown in the table. The relative stiffness for FE-L5 as compared to the control model was 0.97 or a percentage loss of 3\%, and the relative stiffness for FE-L $5 \times 2$ as compared to the control model was 0.93 or a percentage loss of $7 \%$. It was seen that beam FE-L $5 \times 2$ which represented a higher damage exhibited a higher drop of global EI.

Updating the damage parameters confirmed the results from updating using Young's modulus alone. The test results also confirmed that there was no significant loss of stiffness by doubling the volume of the honeycombs. It was seen here that there was 
a stiffness loss of $3 \%$ for the case of the FE-L5 beam, and $7 \%$ loss for the FE-L5 $\times 2$ beam.

\subsection{Comparison of Global EI's}

This section compares the results of global EI obtained from modal testing, static loading test, and finite element modeling and updating. The comparison of global $E I$ from four previously discussed procedures for beam with honeycombed concrete can be seen from Table 3. Fig. 1 shows the relative stiffness at various severity of damage for the beams with honeycombs L5 and L5 22 using the different procedures of modal testing and static load test.

Fig. 5 shows the relative stiffness using the various procedures at different severity of damage as represented by L5 and L $5 \times 2$. For the datum case, all procedures produce similar results. In both cases of L 5 and L $5 \times 2$ there was a general trend of increasing drop of relative stiffness as the severity increased, and the biggest drop in relative stiffness was shown by the procedure using modal testing. It was seen that there was a loss of stiffness of $3 \%$ for the case of FE-L5, and a loss of $7 \%$ for the case of FE-L5×2. The more severe the damage, as evidenced by the higher volume of honeycombs, the higher the loss of stiffness, but it was also confirmed that there was no significant loss of stiffness by doubling the volume of the honeycombs. The finite element analysis indicated the general region of the honeycombs, the exact location of the honeycombs being about the centre of the affected region.

\section{Conclusions}

A simple method of updating the Young's modulus and the honeycombing damage parameters was able to represent the loss of flexural stiffness in the RC beams. The loss of stiffness increased as the as the severity of damage represented by a higher volume of honeycombing increased. It was noted, however, that the effect was less than proportionate. Doubling the volume did not bring about a doubling of loss in stiffness. This is in general agreement with previous work.

\section{REFERENCES}

1. A. Bagchi, E. Murison, A.A. Mufti, A.S. Noman, Evaluation of a rugged FBG strain sensor system for monitoring RC structures, Experimental Techniques, DOI:10.1111/j.1747-1567.2009.00526.x, 2009.

2. E. Caetano, S. Silva, J. Bateira, A vision system for vibration monitoring of civil engineering structures, Experimental Techniques, 32, 6, 54-57, 2008.

3. S.W. Doebling, C.R. Farrar, M.B. Prime, D.W. Shevitz, Damage identification and health monitoring of structural and mechanical systems from changes in their vibration characteristics: a literature review, Rep. LA-13070-MS, Los Alamos Nat Lab, Los Alamos, N.M. 1996. 
4. M.M. FAYYADH, H.A. RAZAK, Z. IsmaIL, Combined modal parameters-based algorithm for damage identification in a beamlike structure: theoretical development and verification, Archives of Civil and Mechanical Engineering, 11, 3, 587-609, 2012.

5. Z. IsmaIL, Application of residuals from regression of experimental mode shapes to locate multiple crack damage in a simply supported reinforced concrete beam, Measurement, 45, 6, 1455-1461, 2012.

6. Z. Ismail, H.A. RazaK, A.G.A. Rahman, Determination of damage location in RC beams using mode shape derivatives, Engineering Structures, 28, 11, 1566-1573, 2006.

7. Z. Ismait, Z. Ibrahim, A.Z.C. Ong, A.G.A. Rahman, An approach to reduce the limitations of modal identification in damage detection using limited field data for non-destructive SHM of a cable-stayed concrete bridge, Journal of. Bridge Engineering, doi:10.1061/(ASCE)BE.1943-5592.0000353, 2012.

8. Z. Ismail, H. Khov, W.L. Li, Determination of material properties of orthotropic plates with general boundary conditions using Inverse Method and Fourier Series, Measurement, Under review, 2012.

9. Z. IsmaIL, A.Z.C. ONG, Honeycomb damage detection in a reinforced concrete beam using frequency mode shape regression, Measurement, 45, 5, 950-959, 2012.

10. A.G.A. Rahman, A.Z.C. Ong, Z. IsmaIl, Effectiveness of impact-synchronous time averaging in determination of dynamic characteristics of a rotor dynamic system, Measurement, 4, 1, 34-45, 2011.

11. A.G.A. Rahman, A.Z.C. ONG, Z. Ismail, Crack identification on rotor shaft using experimental modal data, Experimental Techniques, doi: 10.1111_j.1747-1567.2012.00823.x, 2012.

12. P. ReYNolds, Dynamic testing and monitoring of civil engineering structures, Experimental Techniques, DOI: 10.1111/j.1747-1567.2008.00422.x, 2008.

13. S. Bhalla, S. Tuli, R. Arora, Defect detection in concrete structures using thermal imaging techniques, Experimental Techniques, DOI:10.1111/j.1747-1567.2010.00658.x, 2010.

14. I.S. KHEZEL, The effect of Honeycombing on Modal Response of Reinforced Concrete Beams, MEngSc Thesis, Civil Engineering Department, Faculty of Engineering, University of Malaya, Kuala Lumpur, 2002.

15. W. Omar, L.A. Clarke, The effect of Honeycombing on Shear Capacity of Beams, Proc. 6. Int. Conf. on Concrete Engineering and Technology (CONCET 99), Kuala Lumpur, Malaysia, 1999.

16. J.M. CAICEDo, Practical guidelines for the natural excitation technique (NexT) and the eigensystem realization algorithm(ERA) for modal identification using ambient vibration, Experimental Techniques, 33, 2, 65-75, 2010.

17. G.N. Devi, K. Subramanian, A.R. Santhakumar, Experimental investigations on RC lateral load resisting systems under lateral loads, Experimental Techniques, DOI:10.1111/j.1747-1567.2010.00634.x, 2010.

18. S.-E. Fang, R. Perera, G. De Roeck, Damage identification of a reinforced concrete frame by finite element model updating using damage parameterization, J Sound and Vibration, 313, 3-5, 544-559, 2008.

19. A. Bayraktar, B. Sevim, A.C. Altunişik, T. Türker, Analytical and operational modal analyses of Turkish style RC minarets for structural identification, Experimental Techniques, 34, 2, 49-53, 2010.

20. J.F. Gauthier, T.M. Whalen, J. Liu, Experimental validation of the higher-order derivative discontinuity method for damage identification, J Structural Control and Health Monitoring, 15, 43-61, 2008.

21. T.M. Whalen, The behavior of higher order mode shape derivatives in damaged, beam-like structures, J Sound and Vibration, 309, 426-464, 2008.

22. T.M. Whalen, J. Liu, J.F. Gauthier, Application of the higher order derivative discontinuity method to the I-40 bridge damage detection problem, Proc. 4. World Conf. on Structural Control and Monitoring, San Diego, CA, USA, 2006.

23. M.O. Abdalla, K.M. Grigoriadis, D.C. Zimmerman, Structural Damage Detection Using Linear Matrix Inequality Methods, J Vibration and Acoustics, 122, 4, 448-455, 2000. 
24. J.T.P. Castro, R.D. Vieira, R.A. Sousa, M.A. Meggiolaro, J.L.F. Freire, Dead load evaluation in $R C$ columns using released strain measurements, Experimental Techniques, DOI: 10.1111/j.1747-1567.2009.00605.x, 2009.

25. J.T.S. WANG, C.C. Lin, Dynamic analysis of generally supported beams using Fourier series, J Sound and Vibration, 196, 285-293, 1996.

26. W.L. Li, Free vibrations of beams with general boundary conditions, J Sound and Vibration, 237, 4, 709-205, 2000.

27. P. Ruta, Application of Chebyshev's series to solution of non-prismatic beam vibration problem, $\mathrm{J}$ Sound and Vibration, 227, 449-467, 1999.

28. P. RutA, The application of Chebyshev's polyminials to the solution of non-prismatic Timoshenko beam vibration problem, J Sound and Vibration, 296, 1-2, 243-263, 2006.

29. H. Grandin Jr, Fundamentals of the Finite Element method, Macmillan, NY, 1986.

30. TNO, DIANA Finite Element Analysis, User's Manual - Release 9.2, 2007.

31. P.L. WALter, Validating the data before the structural model, Experimental Techniques, 30, 6, 56-59, 2006.

32. M.I. Friswell, J.E. Mottershead, Finite element model updating in structural dynamics, Dordrecht: Kluwer Academic Publishers, London, 1995.

33. G. Chen, D.J. Ewins, Verification of Finite Element Models for Model Updating, Proc. 19. Int. Modal Analysis Conf., Orlando, Florida, USA, 2001.

34. M. Link, Updating of Analytical Models Review of Numerical Procedures and Application Aspects, Proc. Structural Dynamics Forum SD2000, Los Alamos, New Mexico, USA, 2000.

35. N. Niedbal, F. Klusowski, W. Luber, Updating of Finite Element Model by Means of Normal Mode Parameters, Proc. 13. Int. Seminar on Modal Analysis, K U Leuven, Belgium, 1988.

36. H. Berger, J.P. Chaquin, R. Ohayon, Finite Element Model Adjustment using Experimental Modal Data, Proc. 2. Int. Modal Analysis Conf., USA, 638-642, 1984.

37. R.M. Lin, D.J. Ewins, Model Updating using FRF Data, Proc. 15. Int. Seminar on Modal Analysis, K U Leuven, Belgium, 141-162, 1990.

38. A. Teughels, J. Maeck, G. De Roeck, Damage Assessment by FE Model Updating using Damage Functions, Computers and Structures, 80, 1869-1879, 2002.

39. N.D. Biswa, Finite element model updating, eigenstructure assignment and eigenvalue embedding techniques for vibrating systems, Mechanical Systems and Signal Processing, 16, 1, 83-96, 2001.

40. B. JAISHI, W.X. REN, Finite element model updating based on eigenvalue and strain energy residuals using multi-objective optimization technique, Mechanical Systems and Signal Processing, 21, 2295-2317, 2007.

41. P.G. Bakir, E. Reynders, G. De Roeck, Sensitivity-based finite element model updating using constrained optimization with a trust region algorithm, J Sound and Vibration, 305, 1-2, 211-225, 2007.

42. M.M. Gola, A. Somae, D. Botтo, On theoretical limits of dynamic model updating using a sensitivitybased approach, J Sound and Vibration, 244, 4, 583-595, 2001.

43. S. Kanev, F. Weber, M. Verhaegen, Experimental validation of a finite-element model updating procedure, J Sound and Vibration, 300, 1, 394-413, 2007.

44. M. Sanayei, E.S. Bell, C.N. Javdekar, J.L. Edelmann, E. Slavsky, Damage Localization and FiniteElement Model Updating Using Multi-response NDT Data, J Bridge Engineering, 11, 6, 688-698, 2006.

45. M. Link, L. Zhang, Experience with different Procedures for Updating Structural Parameters of Analytical Models using Test Data, Proc. 10. Int. Modal Analysis Conf., San Diego, New York, USA, 1992.

46. X.H. He, Z.W. Yu, Z.Q. CHEN, Finite element model updating of existing steel bridge based on structural health monitoring, J Central South University of Technology, 15, 3, 399-403, 2008. 


\section{Extended Abstract}

Honeycombing is one of the common damage that can occur in concrete structures. Literature and studies on this phenomenon are, however, limited. The objective of this study was to propose a method of detecting honeycombing damage in a reinforced concrete beam using the finite element model updating technique. A control beam and two finite element models representing different severity of honeycombing damage were constructed using available software and the defect parameters were updated. Analyses were performed on the finite element models to approximate the modal parameters. A datum and a control finite element model to match the datum test beams with honeycombs were also prepared. Results from the finite element model were corrected by updating the Young's modulus and the damage parameters. There was a loss of stiffness of $3 \%$ for one case, and a loss of $7 \%$ for another. The more severe the damage, as evidenced by the higher volume of honeycombs, the higher the loss of stiffness. The test results also confirmed that there was no significant loss of stiffness by doubling the volume of the honeycombs. The finite element analyses indicated the general region of the honeycombs and showed abnormalities with the mode shapes at the ends of the beams.

Remarks on the paper should be

Received November 15, 2011 sent to the Editorial Office

no later than September 30, 2012

revised version

June 6, 2012 